\title{
EDITORIAL
}

\section{Treatment of pulmonary hypertension in interstitial lung disease: do not throw out the baby with the bath water}

\author{
Vincent Cottin
}

$\mathbf{P}$ ulmonary hypertension $(\mathrm{PH})$, group III of the international aetiological classification [1], is a frequent and severe complication of interstitial lung diseases (ILDs), especially idiopathic pulmonary fibrosis (IPF), the syndrome of combined pulmonary fibrosis and emphysema, ILD associated with connective tissue disease, sarcoidosis, pulmonary Langerhans cell histiocytosis and, rarely, other ILDs [2-6]. Although its prevalence varies widely between these conditions, $\mathrm{PH}$, when present, dramatically impacts morbidity and survival.

Despite recent progress with pirfenidone and nintedanib, which reduce the rate of decline in lung function in patients with mild-to-moderate disease $[7,8]$, management of IPF remains largely supportive, with a relentless progression to respiratory failure and death after a median of only 3 years from the time of diagnosis. Precapillary $\mathrm{PH}$ is common in advanced IPF, with a prevalence of 32-46\% [9-12] at right heart catheterisation (RHC) at the time of evaluation for lung transplantation. The haemodynamic severity of $\mathrm{PH}$ in this context is usually mild, although $2-10 \%$ of patients have severe $\mathrm{PH}$ with a mean pulmonary artery pressure (mPAP) greater than $35-40 \mathrm{mmHg}[9,10]$. $\mathrm{PH}$ is associated with increased dyspnoea, decreased exercise capacity as measured by the 6min walk distance (6MWD) and the peak oxygen uptake at cardiopulmonary exercise testing $[9,13,14]$, lower diffusing capacity of the lung for carbon monoxide (DLCO), greater oxygen requirements and reduced survival $[2,9]$. In one study, the 1-year mortality of patients with IPF and associated PH at RHC was $28 \%$ versus only $5.5 \%$ in those without $\mathrm{PH}$ [9]. In subjects with moderate functional impairment, the prevalence of $\mathrm{PH}$ is lower and varies depending upon the procedures used. In a recent series of 101 patients who underwent systematic RHC at the initial evaluation of IPF, PH defined as a mPAP greater than $25 \mathrm{mmHg}$ was present in $14.9 \%$ of patients, and severe $\mathrm{PH}$ with a mPAP greater than $35 \mathrm{mmHg}$ was found in 5\% [15], demonstrating that $\mathrm{PH}$ may develop earlier in the course of disease than previously considered. Even borderline PH (with mPAP 21-24 mmHg) may have prognostic relevance in IPF [15]. The frequency of PH further increases in the presence of common comorbidities, especially

Hospices Civils de Lyon, Reference Center for Rare Pulmonary Diseases, Dept of Respiratory Medicine, Louis Pradel Hospital, and University Claude Bernard Lyon 1, University of Lyon, UMR 754 INRA-Vetagrosup EPHE IFR 128, Lyon, France.

CORRESPONDENCE: Vincent Cottin, Hôpital Louis Pradel, 69677 Lyon Cedex, France. E-mail: vincent.cottin@chu-lyon.fr obstructive sleep apnoea, thromboembolism and cardiac diastolic dysfunction [2], or in the setting of the syndrome of combined pulmonary fibrosis and emphysema [3].

Current guidelines discourage the use of pulmonary arterial hypertension (PAH)-specific therapy in ILD-PH [16] based on insufficient evidence. The primary treatment approach is, therefore, to correct hypoxaemia using supplemental oxygen whenever appropriate, and to consider lung transplantation when not contraindicated by age or comorbidities. However, the pathogenesis of ILD-PH is multifactorial and more complex than only hypoxic pulmonary vasoconstriction. Pulmonary haemodynamics do not correlate with pulmonary function in this setting, and oxygen supplementation rarely reverses $\mathrm{PH}$ in patients with ILD and, especially, IPF. With the exception of corticosteroids, which may provide significant haemodynamic improvement in a few patients with connective tissue disease [17] or sarcoidosis with stage II or III disease [5, 18], PH is not influenced by the systemic therapy given for ILD. Despite significant experience using pirfenidone in Japan, there is no evidence that this drug might impact $\mathrm{PH}$ development or progression in patients with IPF. Parenchymal lung destruction, intrinsic vascular abnormalities, dysregulation of neovascularisation, alteration in mediators and the cytokine milieu, microvascular injuries, possibly autoimmunity and hypoxia collectively contribute to pulmonary vascular remodelling and PH in IPF $[2,19,20]$. Overall, it has become clear that conventional management of the underlying ILD, including use of supplemental oxygen, does not address the issue of associated PH. Similarities between the pathogenesis of fibrosis and that of PAH support therapeutic approaches that target vascular remodelling in ILD-PH.

Given the availability of drugs to treat $\mathrm{PAH}$, the question has long been raised of whether PH might represent a reasonable therapeutic target in ILDs. If achievable, improvement of ILD$\mathrm{PH}$ using specific PAH therapy might conceivably improve functional limitation and symptoms, and possibly survival. Studies have been hampered by the relative rarity of this condition, the concern that PH may be a physiological correlate of the underlying ILD rather than the process driving its worsening outcome, the lack of a consensus definition of severe ("disproportionate") PH in chronic respiratory diseases and, especially, the theoretical risk that vasodilators may contribute to worsening gas exchange through inhibition of hypoxic pulmonary vasoconstriction. Indeed, short-term intravenous prostacyclin experimentally increases ventilation-perfusion 
mismatch and decreases arterial oxygenation (whereas oral sildenafil improves gas exchange in patients with severe lung fibrosis and "secondary" PH) [21]. Another potential risk of PAH therapy is related to frequent pathological lesions of pulmonary veno-occlusive disease in ILDs [22], but reports of pulmonary oedema induced by PAH therapy in ILDs are scarce.

Very few studies have evaluated the efficacy of specific $\mathrm{PH}$ therapy in ILD-PH. In a small open-label, prospective trial using sildenafil (a phosphodiesterase- 5 inhibitor that induces pulmonary selective vasodilation) in 14 patients with IPF and documented PH, COLLARD et al. [16] have observed a 57\% increase in 6MWD. The National Institutes of Health IPF Network study of sildenafil included patients with IPF and DLCO $<35 \%$ of predicted and, therefore, involved some patients with associated $\mathrm{PH}$; however, they were not included based on $\mathrm{RHC}$, and no information was available regarding $\mathrm{PH}$ [23]. This study was negative for the primary end-point of a $20 \%$ change in $6 \mathrm{MWD}$, but a number of secondary end-points suggested a treatment effect, including DLCO, dyspnoea score, quality of life measures and arterial oxygenation [23]. In a post hoc analysis, the small group of patients with echocardiographic evidence of right ventricular dysfunction had a stronger trend toward a treatment benefit, with greater improvement in exercise capacity and quality of life [24]. In addition, several trials have evaluated PAH-approved drugs in IPF, aiming at preserving lung function decline or improving exercise capacity, with exclusion of subjects with evidence of severe $\mathrm{PH}$ on echocardiogram. The dual endothelin-1 receptor antagonists bosentan and macitentan (NCT00903331) demonstrated acceptable tolerance yet no efficacy in patients with IPF [25-27]. Ambrisentan, a selective antagonist for the type-A endothelin receptor, has proven deleterious in patients with IPF and must be avoided in this setting [28].

In the current issue of the European Respiratory Journal, HOEPER et al. [29] report on the results of a 12-week, open-label, pilot trial sponsored by Bayer HealthCare, using riociguat in 22 patients with PH-ILD including 13 with IPF. Riociguat is a recently developed stimulator of soluble guanylate cyclase that restores the intracellular levels of the second messenger cyclic guanosine monophosphate, thereby inducing vasodilation in both a nitric oxide-dependent and independent manner. Riociguat has a generally favourable safety profile and improves exercise capacity, symptoms and pulmonary haemodynamics in PAH and chronic thromboembolic PH [30]. In this study, patients had mPAP greater than $30 \mathrm{mmHg}$ (mean $\pm \mathrm{SD}$ $40 \pm 10 \mathrm{mmHg}$ ) and pulmonary vascular resistance greater than 400 dyn $\cdot \mathrm{s} \cdot \mathrm{cm}^{-5}$ [29]. The primary end-points were safety and tolerability. Six of 22 patients terminated the study drug treatment before the end of the rather short 12-week period due to death or lung transplantation (one patient each), or adverse events (two patients). Two patients experienced pancytopenia related to immunosuppressive therapy. Results regarding efficacy end-points were mostly deceptive. A slight increase was observed in 6MWD, which should not be overemphasised in the absence of randomisation. In the subgroup of patients who underwent follow-up RHC, the mean cardiac output increased and pulmonary vascular resistance decreased with riociguat, while $\mathrm{MPAP}$ was unchanged, suggesting lack of specificity of the drug on the pulmonary vasculature, with greater decrease in systemic than in pulmonary vascular resistance. Arterial partial pressure of oxygen decreased by $7 \pm 12 \mathrm{mmHg}$ at 12 weeks $(\mathrm{p}<0.05)$, corroborating previous concerns that vasodilator therapy can have deleterious effects on gas exchange in ILDs. The combination of increased cardiac output and decreased oxygenation suggests increased shunting and ventilation-perfusion mismatch. This study suffers from limitations inherent to its short-term, non-randomised design and small sample size. The population studied was heterogeneous, and response to PAH-specific therapy might not be equal when in the context of IPF, systemic sclerosis or sarcoidosis.

Despite these mostly disappointing results, the authors should be commended for conducting a clinical trial specifically addressing ILD-PH. Future trials, even pilot studies, should to be randomised and placebo-controlled. It may prove necessary to better characterise the subgroup of patients who could benefit from PAH-specific therapy. Presumably, trials should first be conducted in subjects with disproportionate elevation of pulmonary vascular resistance as compared to the severity of pulmonary fibrosis and restrictive physiology, in whom $\mathrm{PH}$ likely contributes the most to exercise limitation and morbidity. Which end-point will be appropriate in such studies remains to be seen. Therapy may theoretically aim at improving patientreported outcome measures, haemodynamics and long-term outcome, while not impairing gas exchange; however, some of these goals may not be realistic in patients with ILD-PH, who have ILD as a primary cause of chronic respiratory insufficiency that is not amenable to $\mathrm{PH}$ therapy. Of note, there is currently some uncertainty about how to measure efficacy in trials of IPF in general. Some experts have advocated that composite endpoints measuring progression-free survival (morbidity and mortality end-points) might be adequate [31]. What magnitude of treatment effect on a given end-point is considered clinically meaningful and should be targeted also remains to be determined. Prospective PH registries in expert centres [32] with unbiased evaluation of prospectively acquired data may contribute to refining the design of future trials in ILD-PH.

In conclusion, the results presented by HOEPER et al. [29] should in no way be interpreted as the demonstration that targeting $\mathrm{PH}$ in ILD is deceptive. Management of ILD-PH is now entering a new era of active research. Clinical trials are sorely needed to determine whether $\mathrm{PAH}$ therapy might be beneficial in some patients with ILD-PH without imposing a significant risk of oxygenation worsening.

\section{STATEMENT OF INTEREST}

Conflict of interest information can be found alongside the online version of this manuscript at www.erj.ersjournals.com

\section{REFERENCES}

1 Simonneau G, Robbins IM, Beghetti M, et al. Updated clinical classification of pulmonary hypertension. J Am Coll Cardiol 2009; 54: S43-S54

2 Nathan SD, Cottin V. Pulmonary hypertension in patients with idiopathic pulmonary fibrosis. Eur Respir Monogr 2012; 57: 148-160.

3 Cottin V, Le Pavec J, Prevot G, et al. Pulmonary hypertension in patients with combined pulmonary fibrosis and emphysema syndrome. Eur Respir J 2010; 35: 105-111.

4 Le Pavec J, Lorillon G, Jais X, et al. Pulmonary Langerhans cell histiocytosis associated pulmonary hypertension: clinical 
characteristics and impact of pulmonary arterial hypertension therapies. Chest 2012; 142: 1150-1157.

5 Shlobin OA, Nathan SD. Management of end-stage sarcoidosis: pulmonary hypertension and lung transplantation. Eur Respir J 2012; 39: 1520-1533.

6 Cottin V, Harari S, Humbert M, et al. Pulmonary hypertension in lymphangioleiomyomatosis: characteristics in 20 patients. Eur Respir J 2012; 40: 630-640.

7 Noble PW, Albera C, Bradford WZ, et al. Pirfenidone in patients with idiopathic pulmonary fibrosis (CAPACITY): two randomised trials. Lancet 2011; 377: 1760-1769.

8 Richeldi L, Costabel U, Selman M, et al. Efficacy of a tyrosine kinase inhibitor in idiopathic pulmonary fibrosis. $N$ Engl J Med 2011; 365: 1079-1087.

9 Lettieri CJ, Nathan SD, Barnett SD, et al. Prevalence and outcomes of pulmonary arterial hypertension in advanced idiopathic pulmonary fibrosis. Chest 2006; 129: 746-752.

10 Shorr AF, Wainright JL, Cors CS, et al. Pulmonary hypertension in patients with pulmonary fibrosis awaiting lung transplant. Eur Respir J 2007; 30: 715-721.

11 Zisman DA, Ross DJ, Belperio JA, et al. Prediction of pulmonary hypertension in idiopathic pulmonary fibrosis. Respir Med 2007; 101: 2153-2159.

12 Nathan SD, Shlobin OA, Barnett SD, et al. Right ventricular systolic pressure by echocardiography as a predictor of pulmonary hypertension in idiopathic pulmonary fibrosis. Respir Med 2008; 102: $1305-1310$.

13 Glaser S, Noga O, Koch B, et al. Impact of pulmonary hypertension on gas exchange and exercise capacity in patients with pulmonary fibrosis. Respir Med 2009; 103: 317-324.

14 Minai OA, Santacruz JF, Alster JM, et al. Impact of pulmonary hemodynamics on 6-min walk test in idiopathic pulmonary fibrosis. Respir Med 2012; 106: 1613-1621.

15 Kimura A, Taniguchi $\mathrm{H}$, Kondoh $\mathrm{Y}$, et al. Pulmonary hypertension as a prognostic indicator at initial evaluation in idiopathic pulmonary fibrosis. Respiration 2012 [in press DOI: 10.1159/000345221].

16 Collard HR, Anstrom KJ, Schwarz MI, et al. Sildenafil improves walk distance in idiopathic pulmonary fibrosis. Chest 2007; 131 : 897-899.

17 Sanchez O, Sitbon O, Jais X, et al. Immunosuppressive therapy in connective tissue diseases-associated pulmonary arterial hypertension. Chest 2006; 130: 182-189.

18 Gluskowski J, Hawrylkiewicz I, Zych D, et al. Effects of corticosteroid treatment on pulmonary haemodynamics in patients with sarcoidosis. Eur Respir J 1990; 3: 403-407.
19 Farkas L, Gauldie J, Voelkel NF, et al. Pulmonary hypertension and idiopathic pulmonary fibrosis: a tale of angiogenesis, apoptosis, and growth factors. Am J Respir Cell Mol Biol 2011; 45: 1-15.

20 Behr J, Ryu JH. Pulmonary hypertension in interstitial lung disease. Eur Respir J 2008; 31: 1357-1367.

21 Ghofrani HA, Wiedemann R, Rose F, et al. Sildenafil for treatment of lung fibrosis and pulmonary hypertension: a randomised controlled trial. Lancet 2002; 360: 895-900.

22 Colombat M, Mal H, Groussard O, et al. Pulmonary vascular lesions in end-stage idiopathic pulmonary fibrosis: histopathologic study on lung explant specimens and correlations with pulmonary hemodynamics. Hum Pathol 2007; 38: 60-65.

23 Zisman DA, Schwarz M, Anstrom KJ, et al. A controlled trial of sildenafil in advanced idiopathic pulmonary fibrosis. $N$ Engl J Med 2010; 363: 620-628.

24 Han MK, Bach DS, Hagan P, et al. Sildenafil preserves exercise capacity in IPF patients with right ventricular dysfunction. Chest 2013 [in press DOI: 10.1378/chest.12-1594]

25 King TE Jr, Behr J, Brown KK, et al. BUILD-1: a randomized placebo-controlled trial of bosentan in idiopathic pulmonary fibrosis. Am J Respir Crit Care Med 2008; 177: 75-81.

26 King TE Jr, Brown KK, Raghu G, et al. BUILD-3: a randomized, controlled trial of bosentan in idiopathic pulmonary fibrosis. Am J Respir Crit Care Med 2011; 184: 92-99.

27 Gunther A, Enke B, Markart P, et al. Safety and tolerability of bosentan in idiopathic pulmonary fibrosis: an open label study. Eur Respir J 2007; 29: 713-719.

28 Courcier S, Paccioni J-P. Lettre aux professionnels de sante VOLIBRIS $_{\circledR}$ (ambrisentan) ne doit pas être utilisé chez les patients atteints d'une fibrose pulmonaire idiopathique. Saint Denis/Paris, ANSM (Agence Nationale de Sécurité du Médicament et des Produits de Santé), 2012. Available from: http://ansm.sante.fr/ var/ansm_site/storage/original/application/1f5283f43069ea39c44ae6a1952586d8.pdf

29 Hoeper MM, Halank M, Wilkens $\mathrm{H}$, et al. Riociguat for interstitial lung disease and pulmonary hypertension: a pilot trial. Eur Respir J 2013; 41: 853-860.

30 Ghofrani HA, Hoeper MM, Halank M, et al. Riociguat for chronic thromboembolic pulmonary hypertension and pulmonary arterial hypertension: a phase II study. Eur Respir J 2010; 36: 792-799.

31 Vancheri C, du Bois RM. A progression-free end-point for idiopathic pulmonary fibrosis trials: lessons from cancer. Eur Respir J 2013; 41: 262-269.

32 Humbert M, Sitbon O, Chaouat A, et al. Pulmonary arterial hypertension in France. Results from a national registry. Am J Respir Crit Care Med 2006; 173: 1023-1030. 